\title{
Becky Parry \\ POPULAR CULTURE, PARTICIPATION AND PROGRESSION IN THE LITERACY CLASSROOM
}

\begin{abstract}
In this paper I share an account of what happens when a teacher values children's experiences of popular culture in a classroom activity. Drawing on a socio-cultural approach to learning, I suggest that children are not simply enthused when their lived cultures are valued in the classroom, but more fundamentally that they are motivated because they can participate in (and are not excluded from) the learning that is constructed. Drawing on data from a recent media literacy research project, I aim to demonstrate the necessity of including popular culture experiences in literacy teaching in order to ensure that children are able to articulate and develop key conceptual understandings. Furthermore, I suggest that interrogatory pedagogic strategies, (Wells, 2007), including practical productions, are key to ensuring that children are able to make explicit, and then organise and develop their conceptual understandings.
\end{abstract}

\section{Using children's culture}

Marsh and Millard's (2000) influential work, 'Literacy and Popular Culture' is underpinned by the argument that the 'cultural capital' (Bourdieu, 1977) of all children should be recognised, to ensure that their learning experiences are made meaningful. By valuing their popular culture, teachers can ensure that children do not have to reject their home identities in the classroom. In doing so, connections can be made with the interests of children so that their literacy learning will be more motivated. Marsh and Millard further suggest that popular culture can be used to connect children to more high status texts and enable them to develop critical literacy skills.

In her subsequent study of a blogging project, Marsh (2009) also demonstrates that the inclusion of children's home digital literacy practices can be central to the development of a productive pedagogy underpinned by a concern for social justice and equality of opportunity in education. The productive pedagogies model was used as a critical framework in The Queensland School reform longitudinal Study in which over 1000 primary and secondary lessons were observed and analysed (Lingard, 2005). The four dimensions of productive pedagogies were subsequently described as: intellectual quality; connectedness; supportive classroom environments; and engagement with difference. The study concludes that where these four dimensions are apparent, learner agency is advocated. In her study of blogging, Marsh (2009) focuses on the aspect of connectedness, and relevance to children's lives. Marsh suggests that classroom activities should 'recognise children's digital habitus (Bourdieu, 1980 /1990) and enable them to draw on the knowledge and practices they develop in their engagement with new technologies in the home' (Marsh, 2009 p.216).

The need to connect home and school experiences in learning is well researched (although not embedded in curriculum), particularly in the area of early years' research (Marsh, 2004), and also in relation to language (Heath, 
1983) and to popular culture (Dyson, 1998). Indeed the link between popular culture and children's motivation is frequently used as a rationale in literacy activities, and as Willet (2005) demonstrates, when we do explicitly invite children to draw on their experiences of popular culture, the classroom becomes richly populated with the characters and narratives of films, games and television programmes. Furthermore, as Potter (2012) eloquently illustrates, in their production of digital texts, children actively curate their identities through a bricolage of media experiences. Importantly, in both of these examples the inclusion of popular culture enables the children to demonstrate their understandings of narrative and media forms.

In the many examples of research focused on literacy and popular culture or home literacy practices it is evident that it is not just the sheer pleasure of sharing popular culture texts which increases children's motivation in literacy activities (as important as this is). I propose that it is also the ability to fully participate in classroom learning and demonstrate emerging conceptual understandings which heightens children's motivation and prompts learning progression. Through an examination of data derived from a research project focused on media literacy and learning progression, I aim to explore further this proposal. The paper is informed by the work of Vygotsky (1962) whose views about the social construction of knowledge and the ways in which children develop conceptual understanding provide a useful lens through which to examine examples of classroom practice.

\section{The study}

'Developing Media Literacy: Towards a Model of Learning Progression' was an ESRC funded research project instigated by David Buckingham at the University of London, Institute of Education. The project ran from January 2009 until January 2012 and was the first large-scale, systematic research project to explore the practice of media education in schools. The methodological approach taken included action research whereby schemes of activity were collaboratively planned by teachers and researchers and then implemented in each classroom. The specific aim was to develop a model of learning progression in media education which would seek to specify what children of different ages might be expected to understand about media; and how their learning could develop over time, and in the course of a sequence of learning activities.

The data was collected during periods of classroom activity with children in years 2, 4, 8 and 10 and then again when the same groups were in years 3, 5, 9 and 11. The research involved classroom observations, some of which were recorded on audio or video for later analysis. Teachers and students were also asked to complete a questionnaire and were interviewed at a number of stages in the project. The data were analysed in a number of ways, including thematic coding and narrative analysis. In this account I report on data derived from a week of activities that focused on media language and narrative. During this week I observed activities, made video recordings, and collected examples of the texts the children produced. These data were analysed using comparisons with the other school sites as a basis for identifying a series of themes which were then used to further select data including: vignettes from classroom activities, 
examples of texts, and transcriptions of observations. In this article I share data that were selected in relation to one of the themes emerging from our analysis, focusing on pedagogy in relation to the inclusion of popular culture in the classroom.

\section{The participants}

Prior to the start of the research, a group of focus children were identified for each research class. We asked the teacher to suggest a purposive sample of six to eight children whose experiences would vary in terms of gender, class, ethnicity, learning dispositions and social and cultural experiences. The focus children from one year four class ( 8 and 9 year olds) are the main focus of this paper, although other responses are referred to where they are of particular interest.

These children attend a city primary school in the east of England, which is one of a federation of media arts specialist primary and secondary schools. The intake is diverse: an above average proportion of children have English as a second language; are entitled to free school meals; or have a statement of special needs.

The focus children include:

Luke - an articulate and high achieving boy of white British descent.

Maya - an Iranian born girl with an extensive extended family and wide ranging cultural experiences.

Sadia - a girl of Pakistani decent, described by the teacher as lacking a wideranging vocabulary in English.

Manola - who has just joined the class from Spain and is learning English very quickly.

Lee - a boy of white British descent, described as not always fully engaged in school work.

Jade - a white British girl, described as achieving below average attainment in literacy.

Joe - a white British boy, described as having severe physical, behavioural and learning difficulties.

The teacher, Caitlin, was a very experienced primary teacher who had recent experience of senior management in similar primary schools. Caitlin explicitly drew on a range of theories of learning in her work and was particularly keen to ensure learning was extended. Her attitude to media and popular culture was slightly ambiguous as she had many concerns about children's use of popular culture but was keen to undertake media literacy learning activities and recognised the potential value of these to the children.

\section{The rationale for the activity}

The planned activity focused on teaching media language with the aim of enabling children to further understand how the many modes of texts such as films or television programmes combine to suggest meaning. We aimed to offer a space in which the children could draw on their own experiences, making explicit the intuitive ideas they had developed as readers of texts through the analysis and production of new ones. Vygotsky's (1962) distinction between 
spontaneous concepts (concepts children develop through concrete engagement with everyday experience) and scientific concepts (concepts which are abstract and systemized and usually learned during formal schooling) are useful to developing an understanding of the ways in which children move informal understandings of media texts to more formal ones.

Vygotsky suggests that, throughout their schooling, children operate with 'potential concepts', moving between spontaneous concepts and scientific concepts. As Dixon-Krauss (1996) points out, the interaction between spontaneous and scientific concepts is not fully understood, however Vygotsky proposes that a child must use a concept before having control over it, rather than, for example, learning a word before being able to use or comprehend its meaning. Dixon-Krauss summarises this learning as a process of enabling the child to detach the concept from their everyday experience, represent the concept with a sign or word, and place it within a system of relationships.

Vygotksy describes 'spontaneous concepts' as having two elements; 'heaps' (the child will name objects and randomly categorise them) and 'complexes' (the child will not only name objects but will also begin to attribute traits to them and discern relationships between them.) These complexes are evident in children's understandings of media language gained through their exposure to texts. For example, they know from repeat experiences of the same convention, that when a character is shown at the bottom of a staircase and then at the top, this implies the character has moved up the staircase even if the full process is not shown. However, this knowledge often remains an implicit understanding. It can be argued then that children develop 'complexes' in relation to the editing and spatial organization of film, before having any naming vocabulary to describe them. Explicit understanding of these elements is also rarely evident in children's first film productions (Burn and Durran, 2006; Parry, 2013), suggesting that children are likely to continue to operate at the level of 'heaps and complexes,' rather than potential concepts until they encounter formal media teaching, including production.

Although Vygotsky and his contemporaries focused on language, there is increasing recognition that attention also needs to be paid to the development of semiotic tools, that is to say, the creative affordances of particular modes:

Since action is mediated by semiotic as well as material tools, participation in the modes of discourse that organise and interpret action not only provides the context for the learning of language and other semiotic systems, but it also inducts learners into the culture's ways of making sense of experience - its modes of classification, its understanding of means ends relationships, and its aesthetic and moral values.

(Wells and Claxton, 2008 p.4)

As previously suggested children develop understanding of 'semiotic tools' implicitly as readers of the moving image. For example, children recognise that a wizard in a film might wear a cloak and carry a wand, but also that they can be shown flying, through the use of special effects or vanishing through the use of 
editing. Furthermore certain music or sounds might indicate their mood or accompany their actions. However, the process in which the spontaneous concepts, acquired by watching film or television, become scientific concepts which are learnt formally requires further research. If when watching a film, a child understands that the prominent placing of a telephone in a room implies a significant call might be expected, how is that conceptual understanding transformed from an individual observation into abstract and systematic knowledge common to a culture? Furthermore, since concepts in media language are culturally contingent and their meaning dynamic, learners are also asked to tolerate uncertainty, that is to say, to recognise that meanings are not fixed and that their understanding of a concept might need to be adjusted following further experiences. In developing children's understanding of media language learning then, we needed to pay attention to this process and examine the extent to which particular sorts of pedagogic strategies enabled this process of learning.

\section{The activity}

To explore how children's spontaneous concepts about media language might become scientific, the year four children embarked on a week of activities related to scary stories. The primary school teachers had opted to take a holistic approach, rather than limiting their focus to one film or genre in particular, so experiences of horror, superhero and science fiction genres were incorporated. This proved to be significant because this invited the children to draw on what they knew from all forms of storytelling about what makes a story scary.

Activities were devised to enable the research team to understand what children could articulate about narrative and uses of media language and how we could further progress their learning. We aimed to value what children already knew about 'scary' stories by inviting them to bring in DVDs, books, films and games which were personal favourites, and to list the elements of a scary story that they were familiar with. The children were then encouraged to analyse a wide range of scary stories in many different forms, paying attention to specific modes. Addressing the broad question: 'how do these texts suggest fear?' Caitlin, the year four teacher, shared a wide range of resources such as the music from the film 'Psycho', the 'You Tube' mash-up 'Scary Mary' based on Mary Poppins, and a short film about a daughter's fears about her mother's worsening Alzheimer's. Detailed study was undertaken of a television clip of 'Batman', 'Watership Down', 'Coraline', 'A Nightmare Before Christmas' a short film, 'Lucky Dip' ${ }^{1}$ and a written story. Caitlin also encouraged the children to analyse texts in stages; they looked at the whole text, then looked at the different modes within the text (sound, music, dialogue, and image) and considered the effect of their particular composition and combination. The children were also invited to participate in tasks using different modes of expression, again paying particular attention to one aspect or one mode (sound, music, visual) in order to begin to make more detailed and specific observations.

Following an exercise to encourage the children to consider the meaning in relation to shot composition, the children were asked to produce storyboards of

${ }^{1}$ From the BFI resource 'Starting Stories: short films for five to eleven year olds.' 
a selection of film clips. For example in their analysis of 'A Nightmare Before Christmas', a clip was shown and freeze-framed and discussed. The children then created storyboards of the sequence and were asked to pay attention to what was in the frame and what sort of shot was being used and why. Finally, the children undertook productions of their own scary stories in image form using photos on Microsoft Power Point and two further group film productions which included scripting, filming, editing and sound editing were made.

I have chosen to present five selected instances which demonstrate the impact of specific pedagogic strategies on children's conceptual understanding of film language. These instances highlight the critical importance of framing of an activity, attention to multimodality, the role of peer discussion, the choice of text, and practical production. I propose that these approaches were aspects of a productive pedagogy which enabled the children to connect with, interrogate and develop their existing conceptual understandings of story and to begin to make these understandings explicit.

\section{Framing the activity}

Rather than ask the children to share what they knew about the structure of stories in general, the children were asked to focus specifically on scary stories, drawing on their experiences in any form. To frame this activity, children were asked to list the scary elements of films and then put them in categories, thus offering some organising principles (characters, sound, music, settings, storylines, props, camera use). Children were asked to work collectively in small groups and move beyond one specific text example to begin to map their broader experiences. All of the groups were able to describe visible narrative elements such as characters, drawing extensively on contemporary popular children's films and television programmes.

Lee, Luke and Manola became immersed in discussing the scary elements of Harry Potter and digressed into copying out reviews of the books. It could be suggested that in this instance the children were operating at the level of what Vygotksy (1962) describes as 'heaps', the first stage in the development of 'spontaneous concepts', and were not yet able to move beyond specific examples towards abstract generalisations. Further scaffolding involved the teacher in asking a specific set of questions which challenged them to identify elements of the Harry Potter stories according to the criteria they had been given and then to widen their focus from one text to many so that they began to make generalisations.

As children became confident with these generic elements they continued to use them to generate ideas. For example, they suggested 'invisibility cloak' and then also wrote down 'magic cape.' Once they progressed to the category of settings they listed generalised settings such as: 'old castle', 'graveyard', and 'old windy street.' Furthermore, once they began to generate characters they sub-divided them into monsters (goblins, vampires, and zombies) and helpers and civilians. The children in this group were able to respond to the task because they were able to draw on their expertise and affinity with the Harry Potter texts. However, this progression had relied on the teacher providing further scaffolding. 
Although it was not explicitly articulated by the teacher, it was clear that her aim was to enable the children to grasp the notion of abstractions. This demanded a pedagogic stance by the teacher which Wells (2007) describes as 'interrogatory'. That is to say, the children's ideas were expressed, organised and questioned to the extent that they were able to progress from specific examples to begin to make abstract generalisations based on their observations across a range of familiar and new textual experiences.

Sadia, Maya and Jade independently understood the idea of looking for abstracted elements rather than adhering to one example. They produced a complex set of notes and illustrations which were systematic applications of their generalised theories. In their list of props they explained the narrative function of the objects: 'Ring to give you powers'. By contrast with the boys, this group appeared to be operating with 'complexes' which the teacher attributed to Maya's extensive cultural experiences and her providing scaffolding to her peers.

In their suggested plot scenarios this group linked characters with plot functions: Some ghosts might die. Some ghosts might lose their powers. They showed understanding of an underlying narrative arc: They go to a place, they come into danger, they have to survive the danger. In a further example they offered a range of possible sounds which reflected their experiences of moving image distinctly: Screaming sounds. Doors creaking. Lightning. Loud bang. Foot sounds. Owls. When they considered music, they related their observations to key events: Loud music and then it stops like someone's running and suddenly something happened to them. Long notes of music and then a bump in the end. Boo!

The teacher's framing referring to sound, and the inclusion of media texts, enabled the children to consider the role of sound in creating meaning. Although the girls did not initially refer to any camera shots in their lists, the inclusion of the category 'camera shots' encouraged them to visualise examples and then imagine specific examples which they expressed as 'camera moving where the girl went.' (This activity was prior to any teaching of film language.) By framing the activity so that the children's attention was directed to the distinct multimodal elements of scary stories in different forms, their opportunities to share their existing 'repertoires of narrative' (Robinson, 1997) were extended.

\section{Attention to multimodality}

In the subsequent analysis activity the children were invited to pay attention to the type of shots used in the film 'A Nightmare Before Christmas'. The children clearly noticed different aspects of the clip, reflecting on their own emotional responses. They selected different shots as being significant. Some children were clearly better at describing exactly what they saw in drawings rather than in words (Figure 1): 


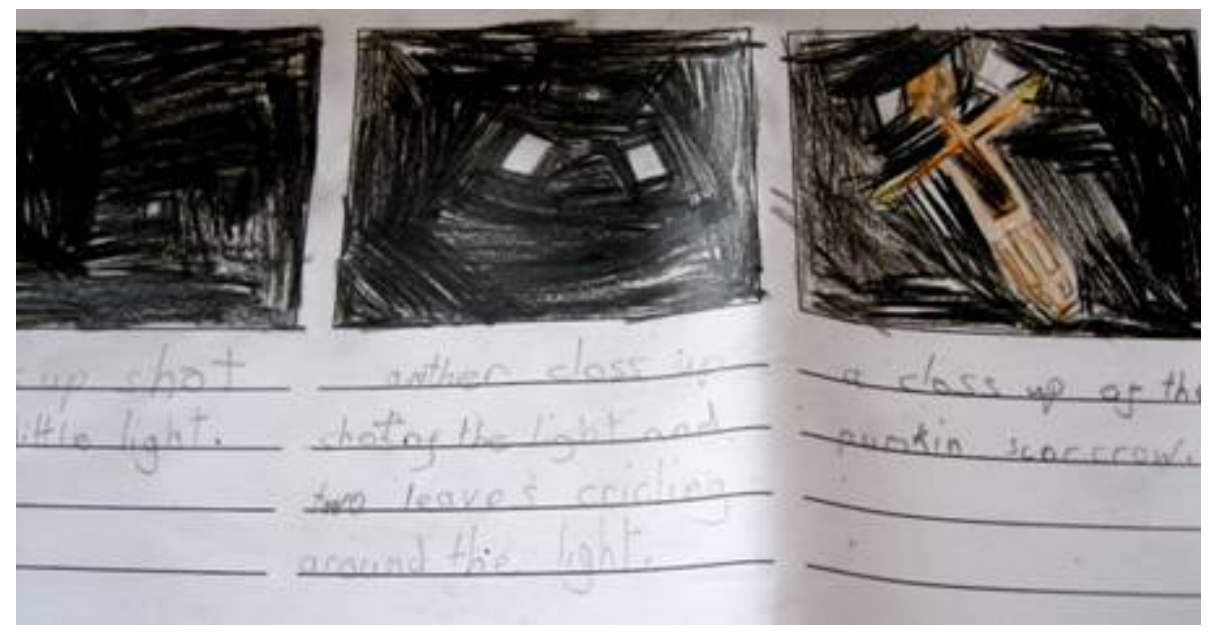

Figure 1: A storyboard from the opening of 'A Nightmare Before Christmas'. Caption 1: Close up shot of a little light.

Caption 2: Another close up shot of the light and two leaves circling around the light.

Caption 3: A close up of the pumpkin scarecrow.

By contrast, Luke and Manola invested time in using descriptive language rather than describing the shots: this mysterious scarecrow twisting its body.

The boys were reluctant to move to a drawing mode, and applied their own rules of writing 'to use descriptive words' to this task, as they did to others. In the use of language we can begin to see the boys' reading of the character of the scarecrow, but not their understanding of shot composition. This resistance perhaps indicated this pair's preference for written expression and that they needed greater support to undertake drawn accounts. The use of a drawn mode of expression in this activity shifted the hierarchy of learners in the classroom and enabled some children to more fully articulate their understandings.

In the next analysis activity the class were explicitly taught the names of some fairly simple shots (medium shot, close up and long shot). This enthused even those for whom drawing was a challenge and led to much more accurate observations of shots. Where children did not have the vocabulary to hand, they attempted to describe shots, imagining and sometimes acting out where the camera was. Manola and Luke referred to a 'closing up and turning up camera', which is an inventive description of a zoom where there is also spiralling animation. Lee and Jade imagined the camera-person to help them conceptualise the shot: Camera man walks forward, gates open, see castle. Having a metalanguage to describe camera use helped the children to be more precise in their observations, however, at this point they had not gained enough specialised vocabulary to articulate their understanding fully. Even so, the focus on camera shots did enable the children to embody and imagine the action of the camera and attempt to understand film composition explicitly. At this point it would have been productive to provide a more complex vocabulary in terms of film language (point of view shots) to enable the children to express the full extent of their understanding in their written descriptions. 


\section{The role of peer discussion}

The children watched a clip of a TV animated version of 'Batman' as a set of individual sequences, making up a whole clip. Thus, their attention was drawn, not only to individual shot choices, but also to camera movement within a shot, and sound. The children were then given a set of 12 stills from the clip in sequence in the form of a storyboard and asked to write notes addressing the questions: 'What's in the frame?' 'What's the camera doing?' 'What sound can you hear? The teacher prompted the children to connect their observations to their interpretations by asking them to say why some choices had been made. This was an interesting extension of the previous storyboarding activity because although they were not drawing, they were being asked to look at images closely. Many of the children initially wrote or drew descriptively, that is to say without attributing meaning, but again with encouragement they could take this much further. For example, Joe, noticed and pointed out a character walking backwards:

Researcher: What does that mean?

Joe: You walk backwards because you want to keep what is in front of you, in your line of sight.

Using 'I' and also enacting this movement as he talked, Joe based his suggestion on his extensive experiences of playing video games. Through group talk and paying attention to one mode, Joe was able to use his experiences of scary texts to make an observation which was somewhere between an everyday spontaneous conceptual understanding and an abstract and concrete understanding of character's point of view and how this relates to audience expectations. Perhaps this is an example of what Vygotky terms a potential concept. This led to a further conversation with others, including Jade, about a film 'Blackwater', (certificate 15) that the children had watched at home: One girl was brave she went forwards not backwards and she's the one who didn't get killed. (Jade)

Thus the discussion between Joe and his peers prompted their consideration of audience expectation of characters' movement and the point of view constructed by the camera in scary films.

The Batman storyboard activity enabled the children to spend time playing back and paying attention to the individual clips, which were available to them on laptops and on the interactive white board. Where they did not have an extensive film language vocabulary the children in Jade's group still attempted to describe complex camera movement: Aeriel shot moved fastly; The camera was going up, following the torch. The teacher insisted that the children linked their observations about what they saw and heard to considerations of meaning. This prompted Jade to notice the affective qualities of the music: the music feels likes something is going to happen.

Based on these examples, it is possible to propose that being descriptive, for example spotting or identifying a close up, is an initial stage in the process of learning to analyse film. However, this process was made richer where meaning making and response were also central. The persistence of the question 'but 
why?' did not always result in the children being able to articulate specific answers but it reinforced the notion of an 'author' of the text with intentions in relation to the audience. The opportunity to undertake meaningful analysis in small peer groups enabled the children to draw on their existing knowledge of film productively and in the case of Joe, shifted his position in the learning hierarchy, positioning him as having expertise which could enrich the learning of his peers.

\section{The choice of text}

Burn and Durran (2006) observe that children tend to draw most of their storyboard shots in mid shot, reasoning that young children are often not consciously aware of the 'grammar' of film. In earlier work I demonstrate that there are some semiotic affordances of film which are quickly apparent to children, such as the choice of costume or music (Parry, 2013). However, equally there are some elements which are more elusive, such as temporal organization. Significantly, by the fourth activity (the analysis of the BFI short animated film 'Lucky Dip'), the children's storyboard drawings reflected careful observation of the shots chosen by the filmmaker. The children were clearly also selecting the shots to draw on the basis of effect on the audience. These depictions exceeded those observed by Burn and Durran (2006), reflecting understanding of more complex shot choices and more complex meaning. I would suggest that the previous tasks, in which the children had paid attention to separate modes or units of meaning, lay useful foundations for this activity. However, alongside framing, multimodal analysis and peer discussion, the text itself clearly also supported their ideas, enabling the children not only to carry on the storyline in terms of devising plots, but also to imagine what these would look like in the style and animated form of the original film.

This activity: storyboarding a scene from a film and then storyboarding a new scene; clearly provided the children with the opportunity to use a concept in order to develop control over it. The children first attempted to represent the combination of signs in the film (a little girl, a rabbit, a pier, point of view shots) and then they represented and recombined this set of signs, exploring their potential meaning further. As Wells and Claxton argue, our toolkit of meaning making is not only print based but is also semiotic, that is to say concerned with images, moving images, and design as well as modes

It is particularly by learning to use these semiotic tools in discourse with others that humans appropriate the culture's dominant way of thinking, reasoning and valuing. And in making them their own and in bringing them to bear on new problems and new situations, they may transform them in ways that add to and potentially improve the culture's shared toolkit of meaning-making resources.

(Wells and Claxton, 2008 p.4)

This activity demonstrated the children's ability to make a set of semiotic resources their own and recombine them to transform meaning. For example, the children drew complex shots which demonstrated more sophisticated understanding than they were able to articulate in their writing. The terms they 
used to describe the shots remained basic: they described long shots and close up shots but they drew point of view shots, low angle and over the shoulder shots (Figure 2):

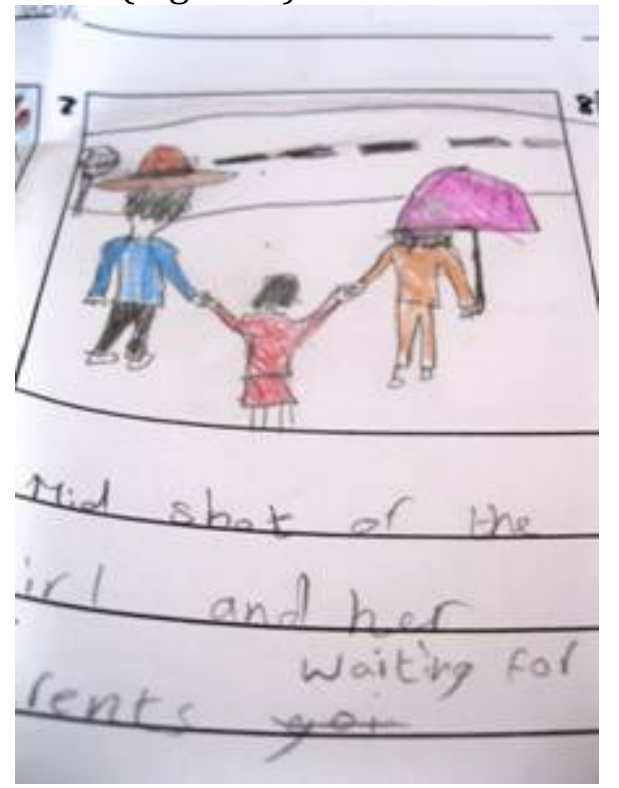

Figure 2: Maya's storyboard image based on the film Lucky Dip

The shots drawn from behind the characters (adopting their point of view, seeing what the characters see), are evident in the original film but here the children have adapted them (see Figures 3 and 4). They have recognised that this shot shows both the character and their object of desire and also a degree of poignancy in terms of distance. They then used this structure but substituted different elements:

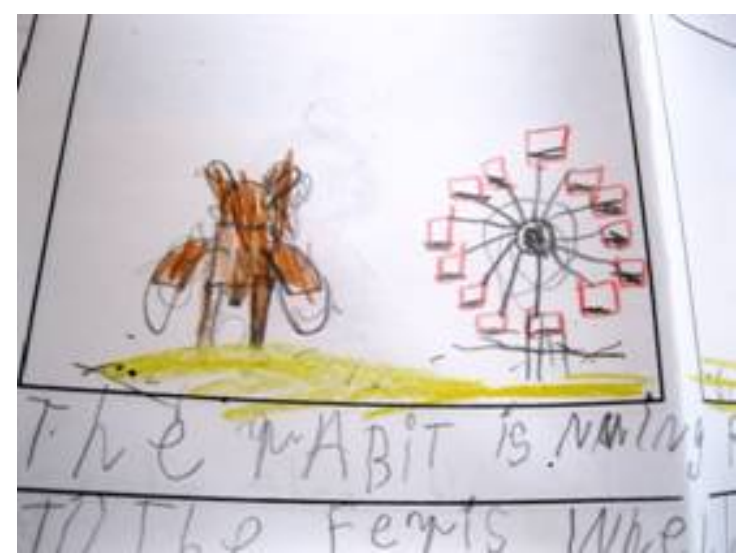

Figure 3: The rabbit is depicted here desiring the big wheel and freedom. 


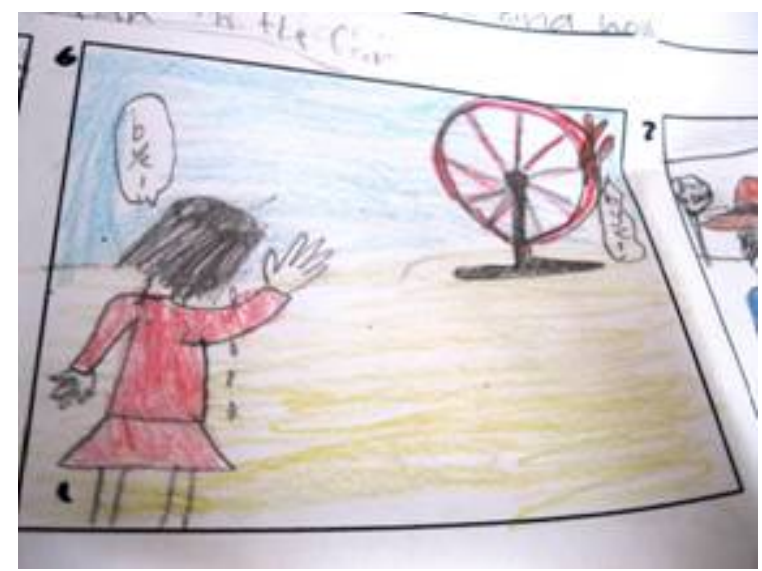

Figure 4: Sadia's little girl desires the rabbit and friendship

All the storyboards above were drawn by children for whom English is an additional language. This drawn mode enabled the children to articulate their rich understandings of narrative and their teacher to value them. Barrs (2000) describes the way in which children use aspects of the style and form of texts to help them in their story writing. Equally here the children were drawing on the particular semiotic affordances of the film text. In this case the children moved from being the audience to being the maker of text and by doing so used the text as a scaffold of ideas.

\section{Practical production}

Following the analysis activities, the children undertook creative work, including the production of a short film entitled 'Who's at the door?', a trailer, their own scary short film, and promotion materials. Interestingly in the children's initial productions they abandoned to a large extent the media language they had been exploring, reverting to simple shots and needing considerable support to recognise the way in which the filming process enabled them to film one sequence and then stop before filming a second. Furthermore, such was the excitement generated by filmmaking that the children became immersed in socio-dramatic play at times even forgetting that they were filmmaking. This first experience of filmmaking is commonly an opportunity simply to learn some technical skills, so it was difficult to judge the extent to which the children could draw on their emerging understanding of film language in this context.

In the children's second productions the camera work became more purposeful and reflected more of the emerging confidence in using the semiotic tools gained from undertaking the storyboard activities. The children also took the decision to include visual representations of their 'monsters', something which they were encouraged by the staff to avoid in their first attempt on the basis that the monster which the audience have to imagine is more scary than one they can see. Great attention was paid to the costume of the monster, the setting, the positioning of the goodies in relation to the baddies and the bodily gestures of the characters. Although some of the decisions did not entirely translate in their films, their intention could be observed in their process of production. Interestingly, the children were still in a socio-dramatic play mode when they created their settings, using available items from school, e.g. chairs were put together to create a bed. This did not seem to concern the children at all but in 
their final films, these props worked less well for the viewer. This became noticeable to the children when they watched their films with an audience and began to see their texts from the audience's perspective.

In terms of scary elements, the children filmed footsteps, doors opening, and screaming characters in close up. They also began to want to attempt shots that exceeded their technical knowledge, for example Lee's group wanted to know how to create the illusion of a ghost walking through a door. This group were explicitly articulating an idea they had seen and wanted to recreate. By contrast Sadia, Maya and Jade intuitively used an effective tilt shot, moving from a low to high angle revealing the 'monster' looking down at the victim's body through a glass door panel. In the sharing and reflecting activity the girls could not remember how they came to decide on this shot. However when they were editing and watching back with peers, they recognised how effective it was. The process of reflecting on their choices led the teacher to point out the type of shot they had used, linking it to the work on Batman they had undertaken. After this dialogue the girls could more explicitly discuss why their audience had 'most liked' that shot and why it was particularly dramatic.

\section{Conclusion}

The data from this action research project strongly suggests that children have rich repertoires of understanding of media language and narrative which they can, if given the appropriate space and encouragement, apply to new texts and their own text productions. There is thus, a strong connection between conceptual understanding and cultural experience. As Wells (2007) argues, immersion, that is to say reading of texts, does not in itself facilitate this process and there is an important role for teachers to create spaces in which children can draw on their cultural experiences to formulate the systematic generalisations which lead to further conceptual understandings.

In terms of implications for pedagogy there are some useful lessons to be learnt. The primary teacher's decision to focus on scary stories across a range of media forms was a key decision which ensured that no one media form was privileged and that children could draw holistically on their experiences of popular culture texts in many forms. This enabled the children to relate to tasks such as organizing their existing knowledge into given categories. As the data also demonstrates, a recursive and staged attention to the meanings suggested by different modes was especially effective in enabling children to be precise about film language. This was further augmented by the use of probing questions which prompted the children to pay attention to meaning and effect. Far from blandly valuing the children's ideas based on popular culture, the teacher took an interrogatory role, which pushed the children to consider meaning and intention directly. By asking: Why? What does it mean? Why has the filmmaker chosen this shot or sound?, the children were not simply observing film language but more importantly drawing on their personal responses to consider the range of possible meanings of a text.

The multimodal approach adopted, which focused attention on the meaning created in the different modes also extended the development of children's 
understandings into an organisational structure: the elements texts are composed of; their separate meaning; and their combined meaning. This appeared to make visible some of the more elusive aspects of moving image texts, especially where the children were given opportunities for extensive repeat viewings and also where they were invited to express or develop their ideas in a range of forms (spoken, written, drawn, film production). These pedagogic strategies enabled children with diverse experiences of text to enter into a shared dialogue with some very productive results.

The activities promoted inclusion, and valued the children's cultural capital with greater equity than a focus on print texts alone might allow. In the week of focusing on film, Joe was able to participate and was motivated to do so, not because he particularly enjoyed scary films, (games were his passion) but because he had knowledge which could contribute to the dialogue. Usually Joe's talk was deemed inappropriate but here it was of great significance to one group's emerging understandings of point of view and distance in filmmaking. Joe was therefore motivated because he had something relevant to say and he was intellectually challenged by his emerging understanding of a set of semiotic tools (gestures, shot composition). What is more, his understanding also prompted others to pay attention to the particular set of signs he had highlighted. In this group, the hierarchy of learners shifted from the perception of Joe as difficult to work with and off- task to someone with expertise. His expertise was taken seriously because it allowed the others in the group to connect with their own viewing experiences. In articulating what he observed he made explicit an understanding he could then potentially use in another context.

The idea that children have assets (Robinson and Mackey, 2006), funds of knowledge (Gonzalez, 2005), or narrative repertoires (Robinson, 1997) is not new. However, it is important to fully understand the implications of ensuring that connecting with these experiences is not merely a cosmetic case of using popular culture to persuade children to engage with literacy. It is fundamental that children can draw on their existing experiences emerging from their lived cultures, in order to progress to the development of 'scientific' concepts in their formal learning. The critical role of pedagogy and popular culture in this process is evident. When we consider how central children's existing understandings are to progression it becomes a pedagogic imperative to enable them to connect with and interrogate their experiences of popular culture and use a range of semiotic modes in their analysis and production of texts.

\section{References}

BARRS, M. (2000) The reader in the writer. Reading, 34.2 pp. 54-60 BOURDIEU, P. (1990) The Logic of Practice. (R. Nice, Trans.). Cambridge, Polity Press. (Original work published in 1980). BOURDIEU, P. (1977) Outline of a Theory of Practice. Cambridge, Cambridge University Press BURN, A. and DURRAN, J. (2006) Digital Anatomies: Analysis as production in media education. In Digital Generations: Children, Young People and New Media. 
Lawrence Erlbaum, Mahwah, NJ pp. 273-293

DIXON KRAUSS, L. (1996) Vygotsky in the Classroom: Mediated Literacy Instruction and Assessment. New York, Longman

DYSON, A. H. (1998) Folk processes and media creatures: reflections on popular culture for literacy educators. The Reading Teacher. 51.5 pp.392-402

GONZALEZ, N., MOLL, L.C., and AMANTI, C. (2005) Funds of Knowledge:

Theorising Practices in Households, Communities and Classrooms. Mahwah, NJ:

Erlbaum

HEATH, S.B. (1983) Ways with Words: Language, Life and Work in Communities and Classrooms. Cambridge, Cambridge University Press

LINGARD, B. (2005) Socially just pedagogies in changing times. International Studies in the Sociology of Education. 15.2 pp. 165-184

MARSH, J. (2009) Productive Pedagogies: Play, Creativity and Digital Cultures in the Classroom, in Willet, R., Robinson, M. and Marsh, J. (eds) Play, Creativity and Digital Cultures. New York, Routledge pp. 200-218

MARSH, J. (Ed.). (2004). Popular culture, new media and digital literacy in early childhood. Oxon, New York: RoutledgeFalmer.

MARSH, J. and MILLARD, E. (2000) Literacy and Popular Culture: Using Children's Culture in the Classroom. London, Paul Chapman Publishing

PARRY, B. (2013) Children, Film and Literacy. New York, Palgrave Macmillan POTTER, J. (2012) Digital media and learner identity: The new curatorship. New York, Palgrave Macmillan

ROBINSON, M., and MACKEY, M. (2006) Assets in the classroom: comfort and competence with media among teachers present and future. In Marsh, J. and Millard, E. (2006) Popular Literacies, Childhood and Schooling. London, New York, Routledge pp. 200-220

ROBINSON, M. (1997) Children reading film and television. London, Falmer Press VYGOTSKY, L. S. (1962) Thought and Language. (E. Hanfmann and G. Vakar, eds. and trans.) Cambridge, MA: MIT Press

WELLS, G. (2007) Semiotic mediation, dialogue and the construction of knowledge. Human Development. 50. 5 pp. 244-274

WELLS, G. and CLAXTON, G. (2008) Learning for life in the $21^{\text {st }}$ century:

Sociocultural perspectives on the future of education. Oxford, Malden, Blackwells Publishers Ltd.

WILLETT, R. Baddies in the classroom: Media education and narrative writing. Literacy. 39.3 pp. $142-148$ 